\title{
Diagnóstico Ambiental da Bacia Hidrográfica do Manancial Balneário da Amizade nos Municípios de Álvares Machado e Presidente Prudente - São Paulo/Brasil
}

\author{
Fernanda Bomfim Soares ${ }^{(\mathrm{a})}$, Antonio Cezar Leal ${ }^{(\mathrm{b})}$ \\ ${ }^{(a)}$ Departamento de Pós-Graduação em Geografia, FCT/UNESP, fbs.geo@ gmail.com. \\ ${ }^{(b)}$ Departamento de Pós-Graduação em Geografia, FCT/UNESP, cezar@ fct.unesp.br. \\ EIXO: BACIAS HIDROGRÁFICAS E RECURSOS HÍDRICOS: ANÁLISE, PLANEJAMENTO E \\ GESTÃO
}

\begin{abstract}
Resumo
O presente trabalho apresenta a metodologia empregada apartir das concepções metodológicas de Rodriguez (1994), Rodriguez e Silva (2013) e Leal (1995), com a realização do Planejamento Ambiental a partir das etapas de Organização, Inventário, Diagnóstico, Prognóstico e Proposições, incluindo a elaboração de mapas temáticos e de síntese, utilizando o Sistema de Informação Geográfica (SIG), Sistema de Posicionamento Global (GPS), trabalhos de campo, análise e sistematização de dados e informações. Porém, devido à complexidade de todo o conteúdo, neste trabalho aborda, apenas, a etapa de Diagnóstico Ambiental da bacia hidrográfica do manancial Balneário da Amizade, localizada nos municípios de Álvares Machado e Presidente Prudente, São Paulo, Brasil, contribuindo para o planejamento ambiental e para o zoneamento ambiental de bacias hidrográficas. Para tanto, realizou-se a revisão bibliográfica sobre conhecimentos teóricos e metodológicos de planejamento ambiental, gestão de bacias hidrográficas, gestão de recursos hídricos e geoecologia da paisagem, bem como sobre identificação e análise da situação das Áreas de Preservação Permanente (APP) e diversas legislações ambientais. A importância desse trabalho se deu pela experiência de discutir um assunto importante regionalmente, mas, também, pelo contato que obteve com trabalhos no exterior durante estágio de pesquisa na Ludwig-MaximiliansUniversitat, em Munique na Alemanha.
\end{abstract}

Palavras-chaves: Planejamento Ambiental;Bacia Hidrográfica; Diagnóstico Ambiental; Paisagem; Balneário da Amizade.

\section{Introdução e Justificativa}

Neste estudo abordaram-se conceitos e práticas fundamentais ao planejamento e zoneamento ambiental de uma bacia hidrográfica em área urbana, tendo como foco a Bacia Hidrográfica do Manancial Balneário da Amizade, localizada em área de expansão urbana dos municípios paulistas de Presidente Prudente e Álvares Machado. A bacia hidrográfica apresenta problemas e conflitos, notadamente no que se refere à proteção do manancial de abastecimento público da cidade de Presidente Prudente.

Para a realização desta pesquisa, baseou-se, inicialmente, em estudos e análises realizadas por Soares (2012). Porém, com o objetivo de contribuir e aprofundar as análises, já iniciadas, sobre o planejamento ambiental, se deu continuidade as fundamentações teóricas iniciadas em 2012, aprofundando a discussão teórica com temas: zoneamento ambiental, geoecologia ambiental, 
paisagem, entre outros, bem como se criou uma base de dados cartográfica para o georeferrenciamento e a elaboração de todos os mapas apresentados, além de propor e gerar subsídios à implementação de políticas públicas de gestão dos recursos hídricos, especialmente pelo CBH-PP, e pelas Prefeituras Municipais de Presidente Prudente e Álvares Machado.

A partir do recorte territorial exposto, este estudo está organizado seguindo a ordem estabelecida pela metodologia proposta por Mateo Rodriguez (1994) e adaptada por Leal (2008), foi realizado o Inventário, Diagnóstico Ambiental, Prognostico e Propostas. Sobre a complementação da proposta de Rodriguez (1994 e 2008) e Rodriguez, Silva e Cavalcanti (2010), foram realizados os estudos das paisagens presentes na bacia hidrográfica do manancial Balneário da Amizade, a partir de uma visão geossistêmica da análise ambiental, baseada na Geoecologia das Paisagens. Porém, é importante destacar que, neste trabalho apresenta-se, apenas, a etapa de Diagnóstico Ambiental da pesquisa. É importante, ainda, ressaltar que foi realizada uma atualização cartográfica das informações adquiridas no trabalho realizado na pesquisa de SOARES (2012) que compuseram a base de dados criadas a partir de cartas topográficas adquiridas pelo Instituto Geográfico e Cartográfico (IGC), trabalhos de campo e, estes, contribuíram para a elaboração dos mapas temáticos e sínteses com o software ArcGIS 10.2, com licença disponível pela Universidade.

\section{Procedimentos Metodológicos}

No desenvolvimento deste trabalho se utilizou da metodologia proposta de planejamento ambiental de Rodriguez (1994 e 2002) e Rodriguez et al. (2004), empregada e aplicada por Leal (1995), a qual a elaboração completa da metodologia é composta por etapas de Inventário, Diagnóstico Ambiental, Prognóstico e Propostasde melhoria do estado ambiental, visando proporcionar uma visão integrada das unidades do meio físico, unidades de uso e ocupação da terra e unidades ambientais da bacia hidrográfica do Manancial Balneário da Amizade. Organograma de trabalho (Figura 1) referente a essa pesquisa descreve as etapas das atividades realizadas para o desenvolvimento da mesma.

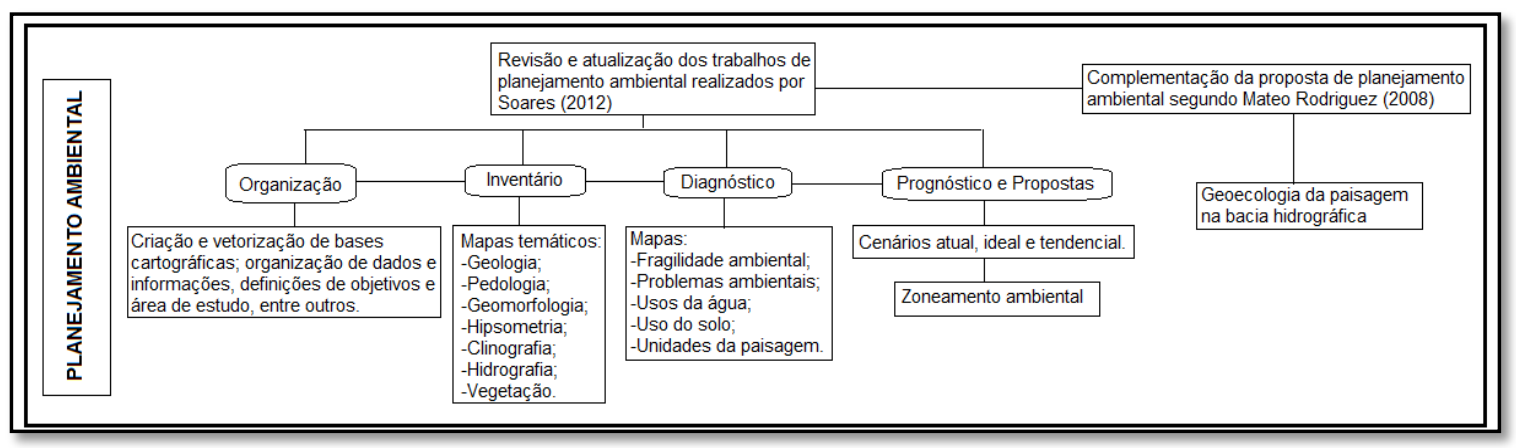

Figura 1 -Organograma das atividades apresentadas nesta pesquisa.

Organização: SOARES, 2015. 
Porém, com já descrito, neste, apresentará a etapa de Diagnóstico Ambiental que focou em apresentar dados e mapas sobre fragilidade ambiental, problemas ambientais, usos da água e do solo e as unidades da paisagem. Para se chegar as informações apresentadas, partiu-se de uma revisão, onde foram atualizados todos os mapas temáticos, tais como: Geologia, pedologia, geomorfologia, vegetação, fragilidade ambiental, problemas ambientais, uso da terra, entre outros.

Os levantamentos de campo tiveram como apoio os vários mapeamentos existentes, com o objetivo de detalhar e caracterizar os diferentes condicionantes do meio físico e de uso e ocupação de terra na bacia hidrográfica. Além disso, os trabalhos de campo foram importantes para a coleta de dados e informações e para a obtenção de imagens e reconhecimento de problemas ambientais, o que são fundamentais para o reconhecimento e análise da área. O tratamento, o georreferenciamento e a vetorização da base cartográfica integrados aos dados e informações, obtidos em campo, foram sistematizados, gerando-se textos, tabelas, gráficos, quadros e mapas de acordo com o desenvolvimento desta pesquisa.

O mapeamento básico foi elaborado nas escalas 1:10.000 e 1:25.000, a partir da compra de duas cartas topográficas (Códigos das folhas: 056/029 e 057/029) do Instituto Geográfico e Cartográfico (IGC), referentes ao Plano Cartográfico do Estado de São Paulo - Edição 1998. Para o tratamento e vetorização das imagens foi utilizado o software ArcGIS 10.2., assim, como para a elaboração dos mapas sínteses e temáticos.Na elaboração das cartas temáticas foram utilizados os diversos levantamentos disponíveis sobre a bacia hidrográfica, as imagens de satélites e os trabalhos em campos, que serviram de base para o melhor detalhamento sobre as temáticas abordadas. Os principais materiais utilizados foram: computador desktop; notebook; pacote de aplicativos Software ArcGIS®; cartas topográficas; imagens de satélite; aparelho de Sistema de Posicionamento Global (GPS); e máquina fotográfica.

Sobre a elaboração dos mapas, o mapa de geomorfologia acompanhada da análise genética é um dos produtos intermediários para a construção do mapa de fragilidade. A execução deste mapa passa pelos procedimentos definidos por Ross (1990 e 1992). Assim, o mapa de fragilidade ambiental decorre do cruzamento das variáveis descritas em mapas anteriores, como: geológico, geomorfológico, declividade e de uso e ocupação da terra na bacia hidrográfica. Os diferentes padrões de fragilidade existentes na bacia hidrográfica foram representados através das Unidades Ecodinâmicas Instáveis (Instabilidade Emergente). Estas unidades foram hierarquiezadas em categorias de graus de fragilidade: Muito Fraca, Fraca, Média, Forte ou Muito Forte, de acordo com a metodologia de Ross (1994). 


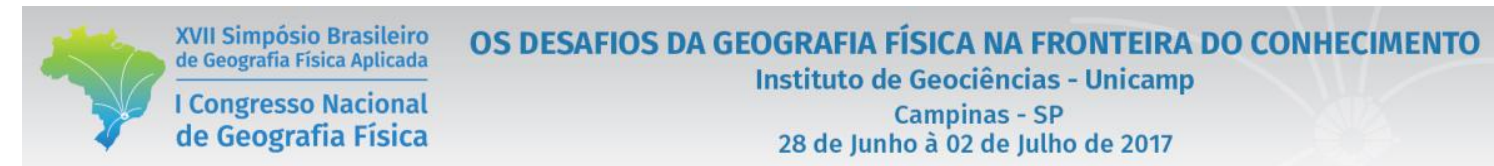

A partir do diagnóstico da fragilidade ambiental, foi possível realizar uma análise integrada dos componentes naturais e do uso que a sociedade faz deles, produzindo e modificando o espaço ao longo da história (ROSS, 2009). A fragilidade ambiental permite avaliar as áreas que sofrem mais impactos, principalmente, da ação antrópica sem considerar o uso racional dos recursos naturais, e que, portanto, necessitam de proteção e recuperação ambiental, sendo importantes indicativos do planejamento ambiental da bacia hidrográfica. Na classificação da fragilidade da bacia hidrográfica em estudo, considerou-se o relevo (morfologia e declividade), tipos de solo e uso da terra. A litologia e o clima não foram considerados na atribuição de pesos por não apresentarem variação na área.O mapa de fragilidade ambiental da bacia hidrográfica do manancial Balneário da Amizade foi gerado a partir do cruzamento espacial do relevo (formas do relevo e declividade), tipos de solo e uso da terra, atribuindo pesos para cada um dos atributos dessas temáticas, classificando-os entre Muito Fraca a Muito Forte grau de fragilidade (ou de 1 a 5), conforme demonstra o Quadro1.

Quadro 1. Grau de fragilidade atribuído às classes de relevo, declividade, solos e uso e ocupação das terras.

\begin{tabular}{|c|c|}
\hline \multicolumn{2}{|c|}{ RELEVO } \\
\hline Classes & Grau de fragilidade \\
\hline Topo & Fraca \\
\hline Colo & Forte \\
\hline Patamar & Fraca \\
\hline Vertente convexa & Fraca \\
\hline Vertente côncava & Forte \\
\hline Vertente retilínea & Fraca \\
\hline Planícies fluviais e alveolares & Muito forte \\
\hline \multicolumn{2}{|c|}{ DECLIVIDADE } \\
\hline Até $6,0 \%$ & Muito fraca \\
\hline De 6,1 a $12,0 \%$ & Fraca \\
\hline De 12,1 a $20,0 \%$ & Média \\
\hline De 20,1 a $30,0 \%$ & Forte \\
\hline Acima de $30,0 \%$ & Muito forte \\
\hline \multicolumn{2}{|c|}{ SOLOS } \\
\hline Argissolos vermelhos & Forte \\
\hline Argissolos vermelho-amarelos & Forte \\
\hline Neossolosflúvicos & Muito forte \\
\hline Gleissolosháplicos & Muito forte \\
\hline \multicolumn{2}{|c|}{ USO E OCUPAÇÃO DA TERRA } \\
\hline Áreas urbanizadas & Média \\
\hline Culturas temporárias & Forte \\
\hline Culturas permanentes & Média \\
\hline Pastagens & Média \\
\hline Silvicultura & Média \\
\hline Área florestal & Muito fraca \\
\hline Área campestre & Fraca \\
\hline Solo exposto & Muito forte \\
\hline Vias de acesso & - \\
\hline
\end{tabular}

Fonte: Trombeta, 2015. 
XVII Simpósio Brasileiro de Geografia Fisica Aplicada

I Congresso Nacional de Geografia Física
OS DESAFIOS DA GEOGRAFIA FÍSICA NA FRONTEIRA DO CONHECIMENTO

Instituto de Geociências - Unicamp

Campinas - SP

28 de Junho à 02 de Julho de 2017

\section{Desenvolvimento}

\subsection{Localização e uso da terra na bacia hidrográfica}

Construído em 1978, através de uma iniciativa conjunta dos municípios de Presidente Prudente e Álvares Machado, o Balneário da Amizade é uma represa artificial de $379.271 \mathrm{~m}^{2}$ com volume total de 2.066.000 $\mathrm{m}^{3}$ para armazenamento de água, na divisa dos municípios supramencionados, no perímetro urbano e no eixo de expansão urbana das cidades sedes municipais, que estão em processo de conurbação.

A bacia hidrográfica do Manancial Balneário da Amizade se localiza no limite entre os municípios de Álvares Machado e Presidente Prudente (Figura 2), e possui uma área de drenagem de, aproximadamente, $20 \mathrm{Km}^{2}$.

A bacia hidrográfica do manancial Balneário da Amizade está inserida na bacia hidrográfica do alto curso do córrego do Limoeiro, que por sua vez encontra-se na bacia hidrográfica do Rio Santo Anastácio, pertencendo, então, a Unidade de Gerenciamento de Recursos Hídricos do Pontal do Paranapanema.

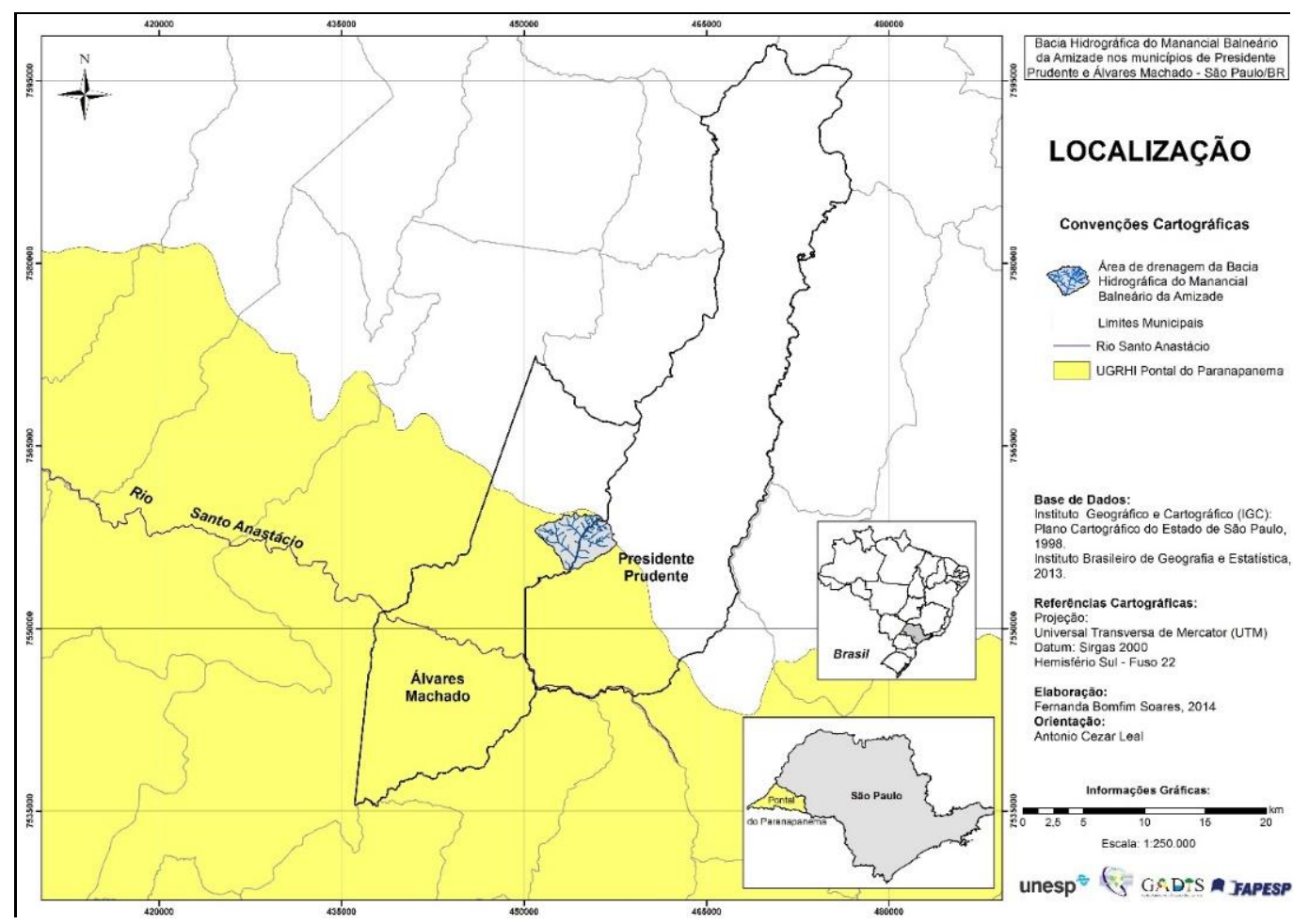

Figura 2. Localização da bacia hidrográfica do manancial Balneário da Amizade.

Fonte: SOARES, 2015.

A partir de trabalhos de campos e imagens de satélite, foi possível a realização do levantamento do uso da terra na área da bacia hidrográfica (Figura 3) e pode-se constatar um alto índice de urbanização na área do entorno do manancial, em ambos os municípios. 


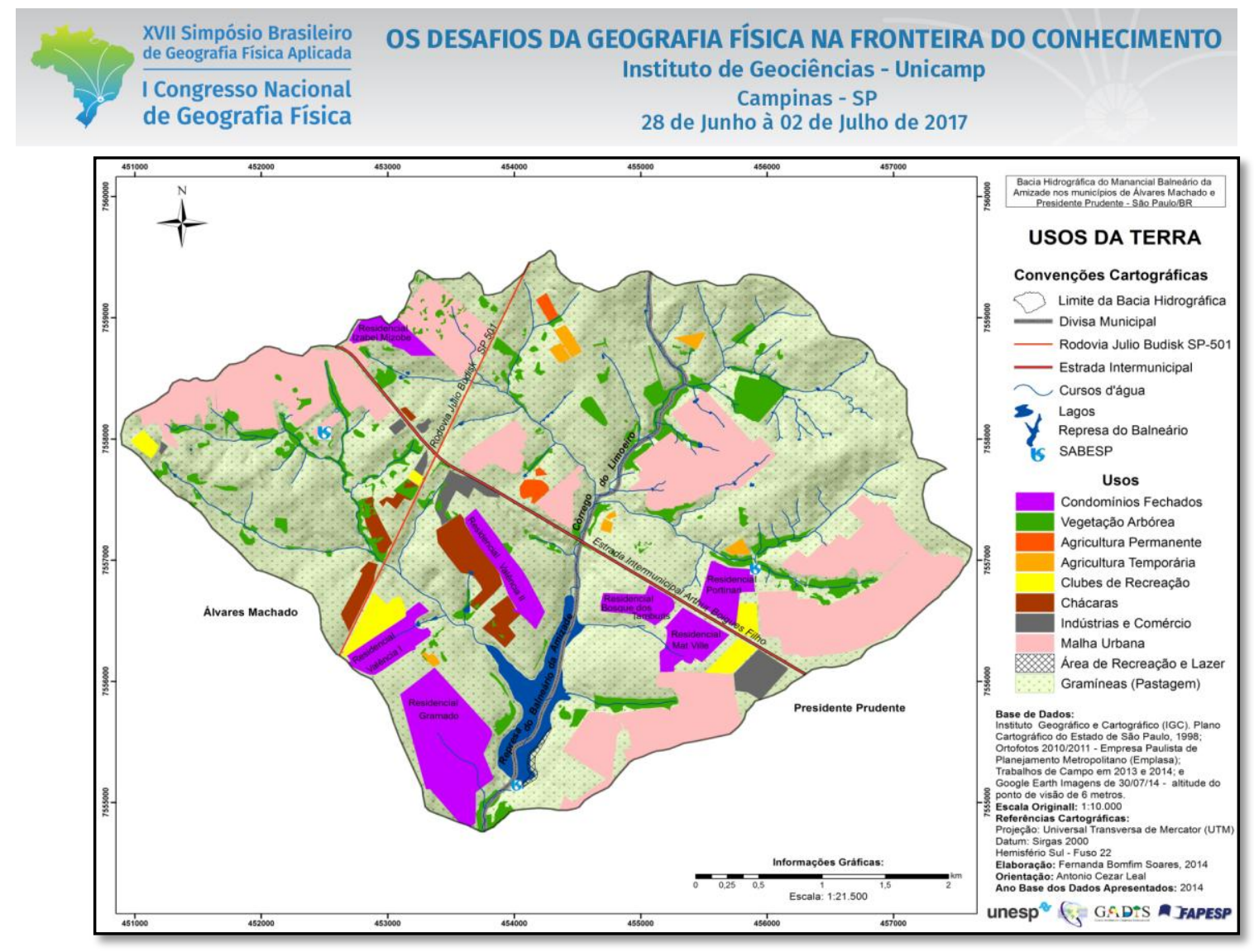

Figura 3. Usos da terra na bacia hidrográfica do manancial Balneário da Amizade. Fonte: SOARES, 2015.

\subsubsection{Problemas Ambientais}

Os problemas ambientais, embora sejam processos físicos, são resultado, em grande maioria, da pressão antrópica exercida sobre o ambiente, não considerando o uso racional e sustentável do território. Todos os espaços da Terra são afetados pelos problemas ambientais, gerando uma crise ecológica, onde as atividades humanas, desenvolvidas a partir do modo de vida da maioria das sociedades modernas, têm grande responsabilidade nesse processo (CUNHA e GUERRA, 2000).

A identificação dos problemas ambientais, como erosão do solo, desmatamento, perda da biodiversidade e assoreamento dos rios, diminuição da qualidade e quantidade da água, entre outros, auxiliam na avaliação integral do estado da bacia hidrográfica. (DIBIESO, 2013)

No mapeamento dos problemas ambientais, foram considerados os pontos de ocorrência dos principais impactos diagnosticados, como desmatamento, descarte irregular de lixo, processos erosivos, entre outros. Esses pontos de ocorrências dos principais problemas ambientais foram identificados e localizados em trabalhos de campo e através de análises e interpretação de imagens de satélite.

Na bacia hidrográfica do manancial Balneário da Amizade, o solo exposto e os processos erosivos são os principais impactos ambientais presentes, seguidos de presença de resíduos sólidos (lixo) e entulho de construção em trechos próximos as principais vias de acesso entre os municípios. 
Os problemas com os processos erosivos, como erosão e assoreamento dos cursos d'água, surgem devido ao mau uso da terra e da falta de planejamento ambiental e urbano durante o processo de urbanização, gerando o não cumprimento das normas e leis ambientais por parte dos órgãos públicos e privados. Já o descarte irregular de resíduos sólidos (lixo) e as queimadas ocorrem devido à falta de conscientização ambiental da população. Em trabalho de campo identificou-se os seguintes problemas como entulhos e descarte irregular de lixo, desmatamento e processos erosivos causados pelo intemperismo físico, químico e antrópico que desagregam os solos formando sedimentos que serão transportados. O depósito destes sedimentos nos cursos d'água constitui o fenômeno do assoreamento. Na bacia hidrográfica do manancial Balneário da Amizade esse processo acontece de maneira intensa, principalmente, nas áreas de vertentes convexas.

As ações antrópicas aceleram este processo através dos desmatamentos, que expõe as áreas à erosão; a construção em encostas que, além de desmatar, tem a erosão acelerada devido à declividade do terreno; as técnicas agrícolas inadequadas, quando se promovem desmatamentos extensivos para dar lugar a áreas plantadas; a ocupação do solo, impermeabilizando-o e aumentando, com isso, a potencialidade do transporte de materiais, devido ao escoamento superficial.

Com as chuvas, sedimentos são levados de seus lugares de origem, indo geralmente parar nos rios mais próximos. Ali, os sedimentos viajam de duas formas distintas, ou por suspensão ou por arraste de fundo. O transporte em suspensão ocorre quando o tamanho das partículas é pequeno o bastante para a velocidade das águas transportá-lo em forma que parece ser dissolvida. No momento em que as águas deixam de correr, há diminuição da velocidade das águas, nota-se a deposição deste material no fundo. O arraste de fundo constitui o "rolamento" das partículas do solo, em especial de areia, no leito do curso d'água. Seu peso não permite ser deslocado em suspensão, mas a velocidade da água é suficientemente forte para impulsioná-lo ao longo do leito. Nas áreas de águas calmas, estes sólidos formam bancos de areia.

Assim, na bacia hidrográfica o processo de erosão e o assoreamento tem se intensificado em razão das ações antrópicas, pois o homem tem modificado o meio natural de forma desastrosa, e uma das consequências é essa erosão acelerada. Os fatores que contribuem para esse cenário são: desmatamentos, queimadas, impermeabilização do solo, drenagem de estradas, urbanização, etc.

Todas as nascentes da bacia hidrográfica se encontram em áreas urbanizadas, o que intensifica o processo de erosão, pois os cuidados ambientais para a proteção desses mananciais não são realizados. Com isso causam danos ao meio ambiente e ao homem que se utiliza de recursos naturais para sua sobrevivência. 
Problemas causados pela intensa urbanização são as deposições irregulares de resíduos sólidos e resíduos de construção e demolição (RDC), descartados em valas próximas aos cursos d' água e nascentes e em áreas com intensos processos erosivos.

A identificação dos problemas ambientais favoreceu a elaboração do mapa de problemas ambientais (Figura 4) e contribuiu para uma visão detalhada da bacia hidrográfica que possui diversos tipos de problemas ambientais relacionados a falta de infraestrutura urbana, despejo ilegal de lixo, processos erosivos (como erosão e assoreamento) e queimadas.

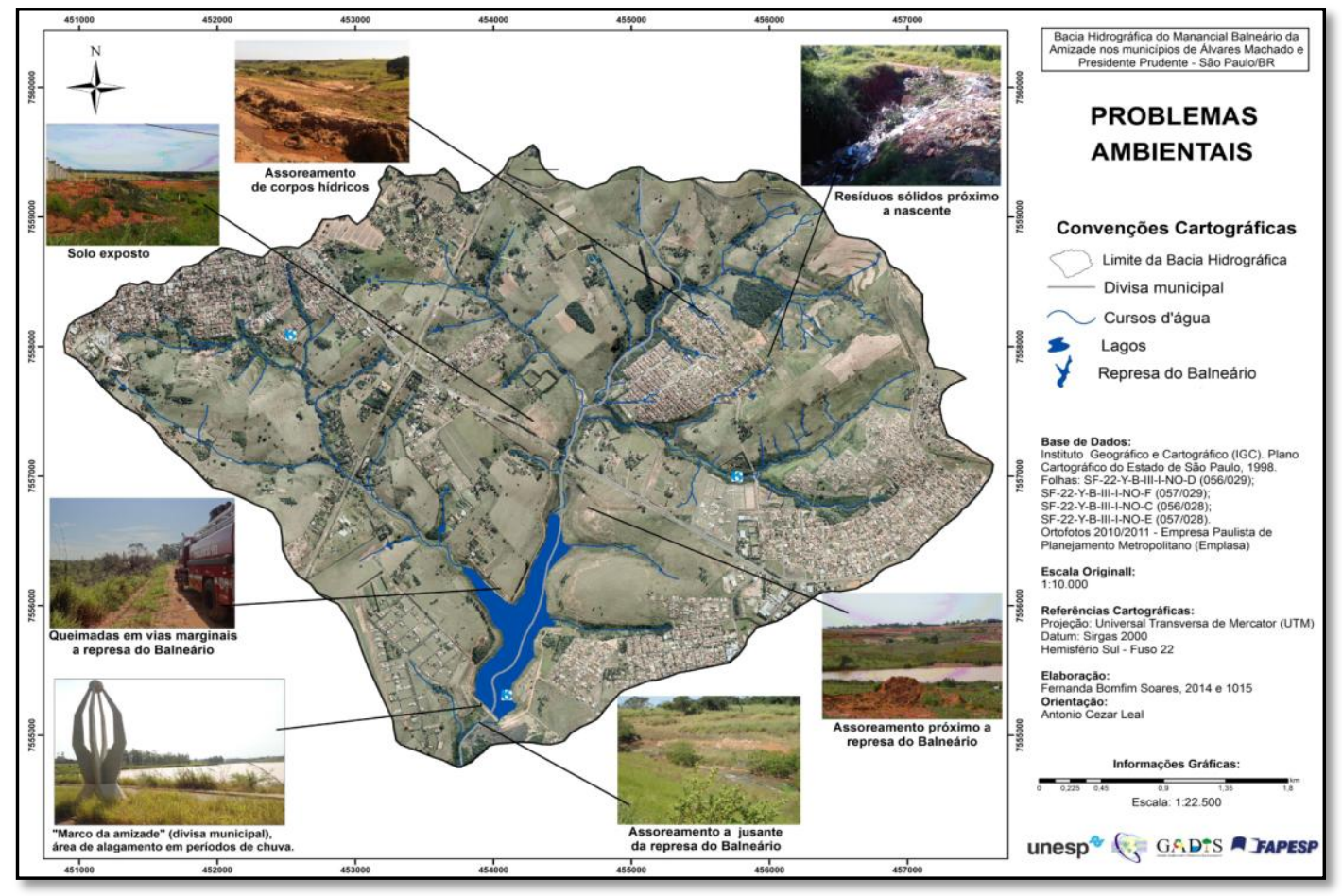

Figura 4. Mapa dos Problemas Ambientais da Bacia Hidrográfica.Fonte: SOARES, 2015.

\subsubsection{Fragilidade Ambiental}

A caracterização da fragilidade potencial e emergente do relevo é um instrumento muito importante no planejamento ambiental, pois sintetiza os elementos analisados no inventário a partir do seu grau de fragilidade, subsidiando as propostas para conservação e preservação ambiental da área.

Embora as atividades humanas causem alterações no ambiente, elas não podem ser entendidas como algo estranho à natureza, mas como um complexo elemento integrado a ela. As ações humanas na natureza a alteram, mas nem sempre de forma negativa.Para que essa análise pudesse ser inserida no planejamento ambiental, esse conceito foi ampliado para Unidades Ecodinâmicas de Instabilidade Emergente e Unidades Ecodinâmicas de Instabilidade Potencial, estabelecendo graus de fragilidade de Muito Fraca (1) a Muito Forte (5), de acordo com os critérios analisados (ROSS, 1994). 


$\begin{aligned} & \text { XVII Simpósio Brasileiro } \\ & \text { de Geografia Fisica Aplicada }\end{aligned}$
$\begin{aligned} & \text { I Congresso Nacional } \\ & \text { de Geografia Física }\end{aligned}$

$\mathrm{Na}$ classificação da fragilidade da bacia hidrográfica em estudo, considerou-se o relevo (morfologia e declividade), solos e uso e ocupação da terra. A litologia e o clima não foram considerados na atribuição de pesos por não apresentarem variação na área da bacia hidrográfica. As informações do relevo revelam a vigor dos processos erosivos, dos riscos de escorregamento/deslizamentos e inundações frequentes. Os solos demonstram a fragilidade em relação a sua erodibilidade. E o uso e ocupação da terra permite hierarquizar os graus de proteção dos solos (ROSS, 1994).

A fragilidade do relevo da Bacia Hidrográfica do Manancial Balneário da Amizade foi gerada a partir do cruzamento espacial entre as variáveis (solos, morfologia, declividade e uso e ocupação da terra), encontrando a fragilidade existente em cada uma dessas variáveis. Como critério de análise da fragilidade foram utilizadas as combinações estatísticas de Moda e Média Aritmética, dependendo das características apresentadas. Em algumas unidades para o cruzamento espacial utilizou-se a Moda, por ser o processo que mais representava a síntese dos elementos, em outras foi usada a Média Aritmética, também por ser mais apropriada para as características da unidade.

Pode ser observado no Mapa da Fragilidade do Relevo (Figura 5) que a maior parte da bacia hidrográfica está inserida no grau de fragilidade "Fraco" aos processos erosivos e o mais recorrente, estando presente em 45,64\% $\left(9,13 \mathrm{Km}^{2}\right)$ da área da bacia hidrográfica. Já as áreas de vertentes com declividade entre $10 \%$ e $20 \%$, em áreas urbanizadas, maior de $20 \%$, próximo a cursos d'água, apresentam grau 5 (muito alta) por apresentarem terrenos não consolidados, ou seja, solo com sedimentos soltos ou impróprios para a construção, e por estarem sujeitas as inundações.

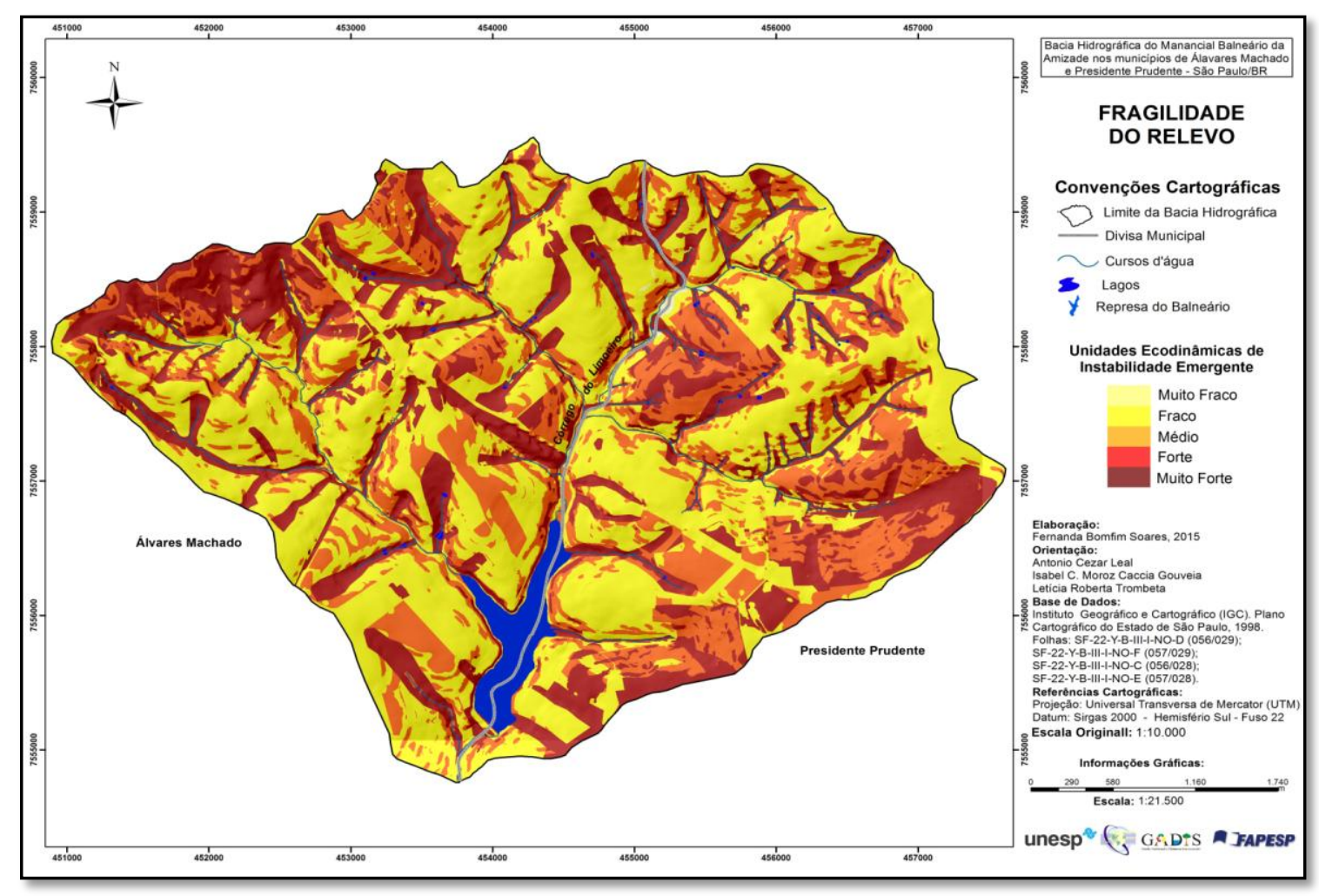


XVII Simpósio Brasileiro

de Geografia Fisica Aplicada

I Congresso Nacional

de Geografia Física

\section{OS DESAFIOS DA GEOGRAFIA FÍSICA NA FRONTEIRA DO CONHECIMENTO \\ Instituto de Geociências - Unicamp Campinas - SP \\ 28 de Junho à 02 de Julho de 2017}

Figura 5. Mapa de Fragilidade Potencial e Emergente do Relevo na Bacia Hidrográfica.

Fonte: SOARES, 2015.

\subsubsection{Usos da Água}

Os municípios em estudo são abastecidos, desde 1976, pela Companhia de Saneamento Básico do Estado de São Paulo (SABESP). Em Presidente Prudente o abastecimento de água ocorre através da captação de $70 \%$ da água no rio do Peixe, localizado a norte da bacia, e 30\% da água no rio Santo Anastácio, ao sul da bacia hidrográfica. E Álvares Machado o abastecimento público ocorre através de captação por poços superficiais e, também pela captação de água no rio do Peixe.

De acordo com o Engenheiro e Diretor da SABESP de Presidente Prudente, a represa do Balneário da Amizade é um manancial de chuva e é a terceira opção para a captação e abastecimento de água em Presidente Prudente. Além disso, o Balneário da Amizade é um manancial para captação estratégica e de emergência, no caso de ocorrer o rompimento de alguma adutora de captação no Rio do Peixe, que fica a 40 km da estação de tratamento e distribuição de Presidente Prudente.

Sabe-se que represa do Balneário da Amizade é de suma importância para o abastecimento público e para a economia de Presidente Prudente, porém seus cursos d'água se encontram em estado lastimável. Muitas nascentes estão assoreadas e outras deixaram de existir, devido ao alto nível de degradação que sofreram durante os anos com usos inadequados.

É importante, ainda, ressaltar que toda utilização legalizada dos recursos hídricos no Estado de São Paulo é liberada e outorgada pelo Departamento de Águas e Energia Elétrica (DAEE). A outorga do uso da água é um importante instrumento disposto na Lei Federal N 9433/1997 (Lei das Águas) e na Política Estadual de São Paulo (Lei 7663/1991) e que em períodos de escassez de água, em algumas regiões brasileiras, o controle no uso dos recursos hídricos é primordial para garantir a sua disponibilidade.

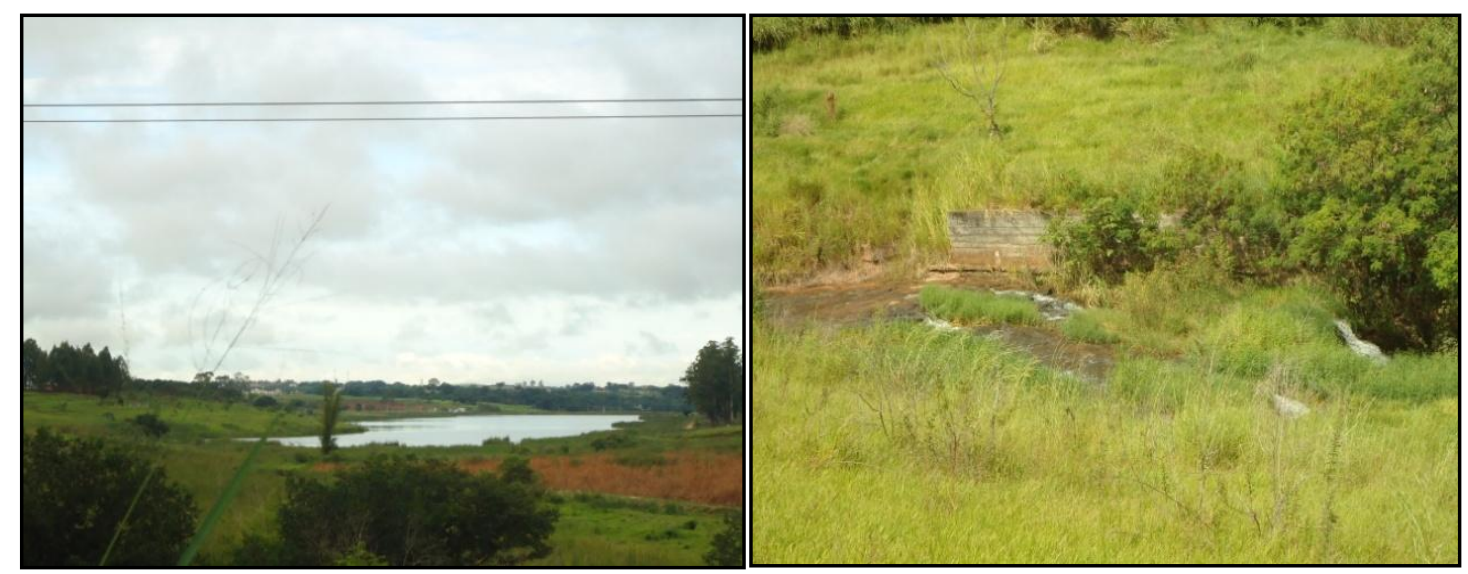


XVII Simpósio Brasileiro

de Geografia Fisica Aplicada

I Congresso Nacional

de Geografia Física

\section{OS DESAFIOS DA GEOGRAFIA FÍSICA NA FRONTEIRA DO CONHECIMENTO \\ Instituto de Geociências - Unicamp Campinas - SP \\ 28 de Junho à 02 de Julho de 2017}

Figuras 6 e 7. Represa do Balneário da Amizade e canal a jusante da barragem da represa do Balneário da Amizade. Fonte: SOARES, 2015.

Os usos que devem ser outorgados pelo DAEE são aqueles que estarão sujeitos a derivação de água de seu curso ou depósito, superficial ou subterrâneo, para a utilização no abastecimento urbano, industrial, agrícola e para qualquer outra finalidade; e, os lançamentos de efluentes nos cursos d'água, de acordo com as legislações federal e estadual por diversos tipos de usuários (DAEE, 1996).

$\mathrm{Na}$ análise de uso da água da bacia hidrográfica foram considerados somente os usos outorgados pelo DAEE. A maior parte está próxima aos principais cursos d'água da bacia hidrográfica, próximo à área urbana dos municípios, sendo, principalmente, os usos de captação de água subterrânea (Figura 8).

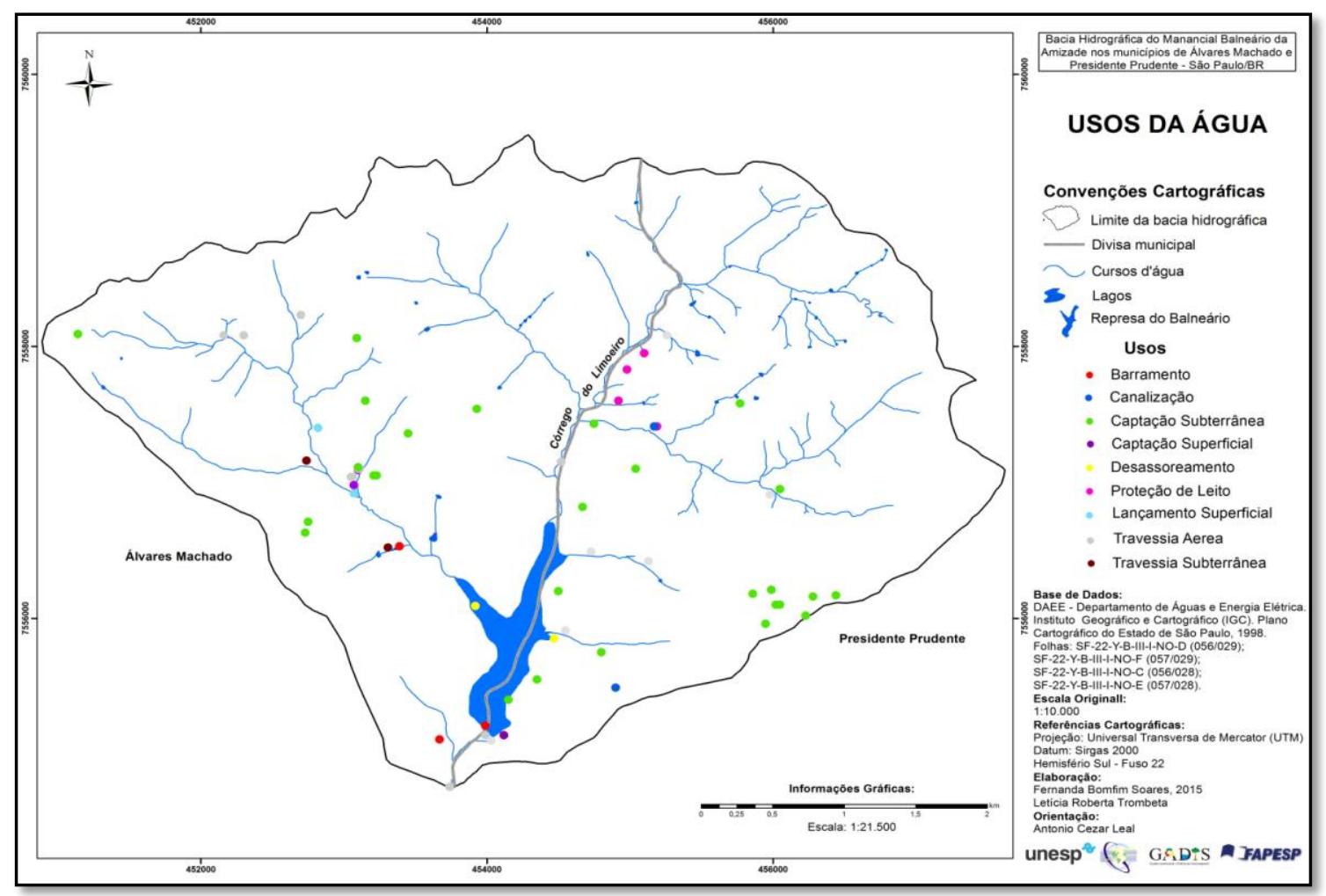

Figura 8. Mapa dos Usos da água na bacia hidrográfica. Fonte: SOARES, 2015.

\subsubsection{Unidades da Paisagem da Bacia Hidrográfica}

As unidades da paisagem consistem na síntese entre os elementos da paisagem natural e os elementos da paisagem antrópica, definindo as homogeneidades existentes no espaço. Cada unidade da paisagem, com o detalhamento das suas características, pode servir como um território de intervenção de ações para melhoria da qualidade ambiental. 
XVII Simpósio Brasileiro

de Geografia Fisica Aplicada

I Congresso Nacional

de Geografia Física

\section{OS DESAFIOS DA GEOGRAFIA FÍSICA NA FRONTEIRA DO CONHECIMENTO \\ Instituto de Geociências - Unicamp Campinas - SP \\ 28 de Junho à 02 de Julho de 2017}

De acordo com Dibieso (2013, p.223), a fim de contribuir com o planejamento ambiental e a gestão da bacia hidrográfica é realizada a Compartimentação da paisagem em segmentos denominados Unidades de Paisagem ou Unidades Ambientais. Para estas Unidades devem ser estabelecidas diretrizes, metas e normas específicas para as diferentes porções do território, buscando garantir maior eficácia na recuperação, conservação e proteção dos recursos hídricos.Assim, a utilização de ferramentas de geoprocessamento tem papel essencial na identificação e concretização das unidades da paisagem, sobretudo com o emprego do Sistema de Informação Geográfica. A elaboração de uma base cartográfica única para cada um dos elementos possibilita, mediante a análise espacial, integrar toda a informação para o desenvolvimento do mapa de paisagem (CHÁVEZ e PUEBLA, 2013).

Com isso, a partir da sobreposição dos mapeamentos de pedologia, geomorfologia, hipsometria, declividade, fragilidade ambiental e uso da terra, foi possível gerar o mapa de unidades da paisagem da bacia hidrográfica. Com a interpretação dos mapas pode-se determinar unidades com características semelhantes que representam atributos importantes da área. Porém, é importante citar ainda, que quanto maior a escala de detalhamento do mapeamento, maior a diversidade das unidades da paisagem. Assim, o mapa de Unidades da Paisagem (Figura 9) representa, de forma sintetizada, os dados e as informações sobre a área de estudo. Esses estudos de mapeamento auxiliam na caracterização e organização do espaço, como base para o estabelecimento das ações futuras. O quadro 2 apresenta as Unidades Ambientais, obtidas após análises na bacia hidrográfica. As Unidades da Paisagem foram divididas em quatro grupos (I, II, III, IV) e subdivididas em três categorias (A, B e C), sendo a categoria $\mathrm{A}$ referente à vegetação, a $\mathrm{B}$ referente a áreas construídas e a $\mathrm{C}$ referente às condições específicas do solo:

Quadro 2. Classificação das categorias das Unidades da Paisagem.

\begin{tabular}{|c|c|c|}
\hline Unidades Físicas & Características de uso e ocupação da terra & $\begin{array}{c}\text { Unidades da } \\
\text { Paisagem }\end{array}$ \\
\hline \multirow{3}{*}{ Unidade I } & Áreas construídas & Unidade I B \\
\cline { 2 - 3 } & Pastagem e solo exposto & Unidade I C \\
\hline \multirow{3}{*}{ Unidade II } & Vegetação & Unidade II A \\
\cline { 2 - 3 } & Áreas construídas & Unidade II B \\
\cline { 2 - 3 } & Agricultura, Pastagem e Solo exposto & Unidade II C \\
\hline \multirow{3}{*}{ Unidade III } & Vegetação & Unidade III A \\
\cline { 2 - 3 } & Áreas construídas & Unidade III B \\
\cline { 2 - 3 } & Agricultura, Pastagem e Solo exposto & Unidade III C \\
\hline Unidade IV & Áreas construídas & Unidade IV B \\
\cline { 2 - 3 } & Pastagem e Solo exposto & Unidade IV C \\
\hline
\end{tabular}

Org. SOARES, 2015. 


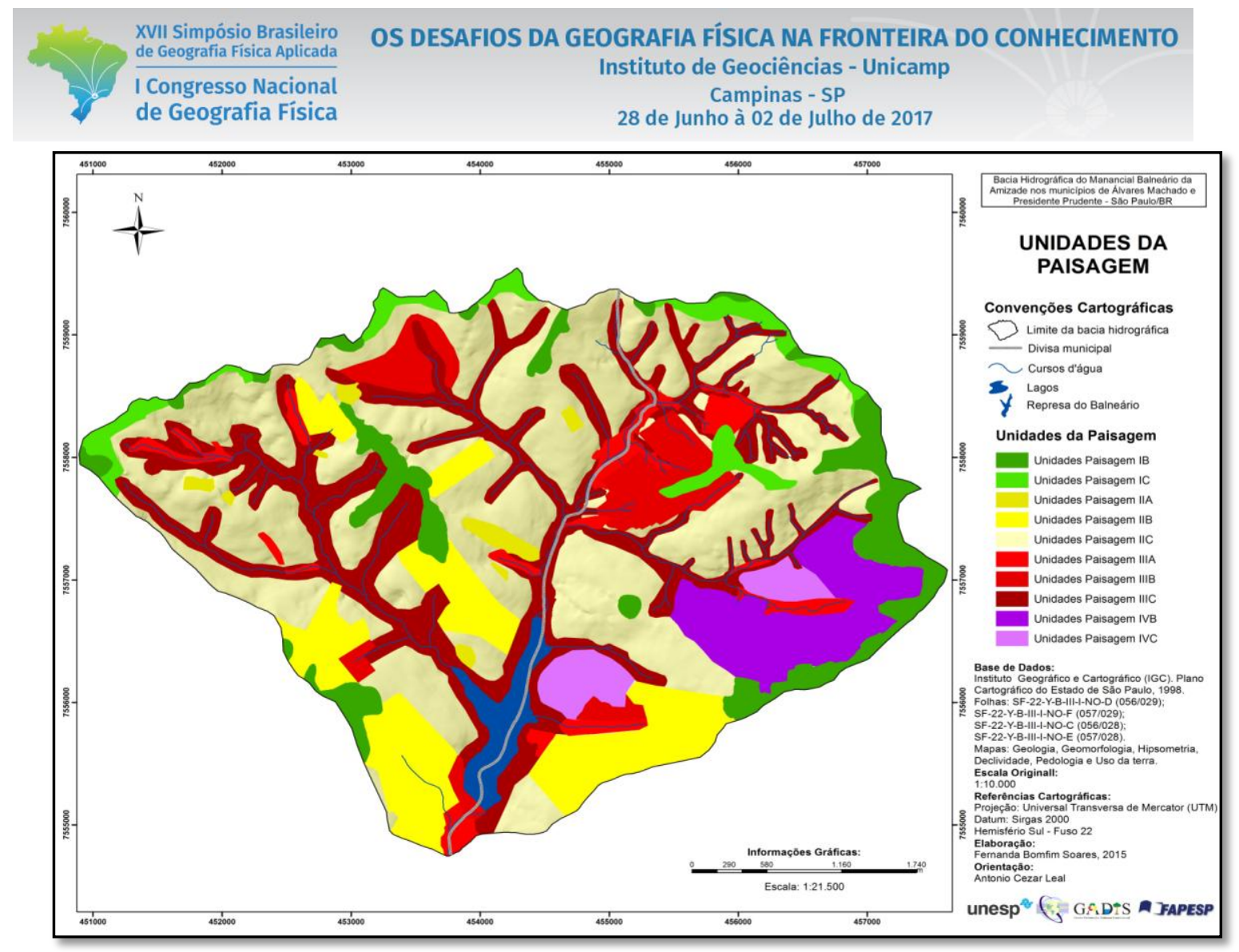

Figura 9. Mapa das Unidades da Paisagem da bacia hidrográfica. Fonte: SOARES, 2015.

\section{CONSIDERAÇÕES FINAIS}

Diante das necessidades do mundo urbano, o meio ambiente é o primeiro a ser sufocado e impedido de fazer o seu importante papel de proteção para dar lugar aos concretos e asfaltos que são símbolos de um "mundo desenvolvido". Assim, como acontece em grandes metrópoles, em pequenas e médias cidades, como é o caso de Álvares Machado e Presidente Prudente, esse avanço do concreto sobre as áreas verdes, também acontecem sem planejamento necessário, favorecendo a expansão urbana, mas destruindo o meio natural, como as áreas verdes, corpos hídricos e o solo.

Com a realização deste trabalho e com os resultados alcançados foi possível obter uma visão integrada de toda a bacia hidrográfica podendo, assim, realizar um trabalho amplo e dinâmico de acordo com as características e necessidades físicas e ambientais da bacia hidrográfica. Os resultados obtidos confirmam que as etapas propostas na metodologia escolhida são fundamentais para a construção do planejamento ambiental.

Este trabalho ressaltou a importância da análise integrada para estudos ambientais na utilização das Unidades da Paisagem. Assim, a falta de mudança no enfrentamento dos problemas ambientais e da degradação da natureza tem comprometido o estado de equilíbrio do ambientee, consequentemente, dos recursos hídricos. 
Sobre os recursos hídricos, é possível afirmar que a migração das nascentes ou até mesmo o desaparecimento de algumas ocorre devido ao abaixamento do nível freático, está hipótese é confirmada com o indício de que o rio não nasce no mesmo lugar com o passar dos anos e a vegetação nativa segue sendo removida, aumentando os impactos ambientais. É possível, ainda, afirmar que no histórico de ocupação da bacia hidrográfica do manancial Balneário da Amizade as áreas da bacia hidrográfica que foram ocupadas são as piores devido ao grau de declividade dos terrenos. Isso ocasiona e concentra sérios impactos ambientais, como os ligados aos processos erosivos. Bem como é possível apontar as imobiliárias e os donos das terras como os principais agentes formadores e construtores do relevo, pois esses imprimem aspectos sociais, como os de estruturas urbanas, que valorizam e direcionam a expansão urbana a partir de decisões políticas fundamentadas em interesses econômicos.

Espera-se que o resultado descrito neste trabalho possa estimular o estudo e pesquisas que contribuam para o disciplinamento do uso das terras, bem como a recuperação e manutenção da qualidade ambiental da área, de modo a garantir a proteção desse ambiente. E que também auxilie a gestão da bacia hidrográfica pelos órgãos competentes e pela população, a fim de conter a expansão urbana irregular e proteger os mananciais.

\section{Agradecimentos}

À FAPESP pelo financiamento integral da pesquisa, ao orientador Prof. Dr. Antônio Cezar Leal e ao Grupo de Pesquisa em Gestão e Dinâmica Socioespacial (GADIS) da FCT/UNESP.

\section{Referências Bibliográficas}

ÁlVARES MACHADO, PREFEITURA MUNICIPAL. Plano diretor do município de Álvares Machado SP. Documento cedido em novembro de 2010.

ÁLVARES MACHADO, PREFEITURA MUNICIPAL. Plano de macrodrenagem do município de Álvares Machado. 2009.

CHÁVEZ, Eduardo Salinas; PUEBLA, Adonis M. Ramón. Propuesta Metodológica Para La DelimitacionSemiautomátizada De Unidades De Paisaje De Nível Local. Revista do Departamento de Geografia, v.25, p.1-19, 2013.

CAVALCANTI, A.P.B. e RODRIGUEZ J.M.M. O Meio Ambiente: histórico e contextualização. In: CAVALCANTI, A.P.B. (org). Desenvolvimento sustentável e planejamento: bases teóricos e conceituais. Fortaleza: UFC - Imprensa Universitária, 1997, p.9-24.

CAVALCANTI, C. Economia e Ecologia: problemas da governança ambiental no Brasil. Revista Iberoamericana de Economia Ecológica, v. 1, p.1-10, 2004.

DIBIESO, Eduardo Pizzolim. Planejamento Ambiental da bacia Hidrográfica do Córrego do Cedro Presidente Prudente/SP. Presidente Prudente, 2006. Dissertação (Mestrado). Universidade Estadual Paulista, Faculdade de Ciências e Tecnologia, 2006, 157p. 
HASDENTEUFEL, P.; RODRIGUEZ, J.M.M.; BAUME, O. Integrated ecosystem based studies as a tool for sustainable environmental management. The Río Quibú (Havana, Cuba) case study. Geography, Environment, Sustainability. , GES , 92-101, Petersburg, 2008.

IBGE. Instituto Brasileiro de Geografia e Estatística. Manual técnico de uso da terra. 3. a ed. Rio de Janeiro: IBGE, 2013.

Censo demográfico 2010. Rio de Janeiro, 2010.

IPT - Instituto de Pesquisas Tecnológicas do Estado de São Paulo. Mapa Geológico do Estado de São Paulo, 1:500.000. São Paulo, IPT. 2v. (IPT, Monografia 6, Pub. 1184), 1981a.

IPT - Instituto de Pesquisas Tecnológicas do Estado de São Paulo. Mapa Geomorfológico do Estado de São Paulo, 1:1.000.000. São Paulo, IPT. 1981b.

LEAL, A.C. Gestão das Águas no Pontal do Paranapanema - São Paulo. Campinas, 2000. Tese (Doutorado em Geociências - Área de concentração em Administração e Política de Recursos Minerais) - Inst. de Geociências - UNICAMP, 299p.

LEAL, Antonio Cezar. Gestão das Águas no Pontal do Paranapanema. 2000. Tese (Doutorado em Geociências) - Instituto de Geociências, Universidade Estadual de Campinas, Campinas, 2000.

LEAL, Antonio Cezar. Meio ambiente e urbanização na microbacia do Areia Branca-Campinas, SP. Rio Claro, 1995. Dissertação (Mestrado em Geociências e Meio ambiente) - IGCE Campus de Rio Claro, 1995, $154 \mathrm{p}$.

PRESIDENTE PRUDENTE. Projeto de Revitalização do Balneário da Amizade. Disponível em: <http://www.presidenteprudente.sp.gov.br>, acesso em 03 de fev. de 2011.

RODRIGUEZ, José Manuel Mateo. Apuntes sobre geografia de lospaisajes. Havana, Cuba, 1984.

RODRIGUEZ, M. M. Planejamento Ambiental como campo de ação da Geografia. In: CONGRESSO BRASILEIRO DE GEÓGRAFOS, 5, 1994, Curitiba/PR. Anais. Curitiba: AGB, 1994. v.1, p.582-94.

RODRÍGUEZ, J. M. M., HASDENTEUFEL, P., MANENT, M. B., FERNÁNDEZ, I. V. Sostenibilidad espacial y ambiental de La província Ciudad de La Habana. Informe de lós resultados delproyectoCaesar. Cuidad de La Habana: EditoralUniversitaria, 2008.

RODRIGUEZ, J.M.M. Planificación Ambiental; Editorial Félix Varela, La Habana, 2008.

RODRIGUEZ, José M. M. et al. Geoecologia das Paisagens: uma visão geossistêmica da análise ambiental. 3. Ed. Fortaleza: Edições UFC, 2010.

RODRÍGUEZ, José Manuel Mateo; SILVA, Edson Vicente da; LEAL, Antonio Cezar. Planejamento Ambiental em Bacias Hidrográficas. In: SILVA, Edson Vicente da; RODRÍGUEZ, José Manuel Mateo; MEIRELES, Antônio Jeovah de Andrade (Org.). Planejamento Ambiental e Bacias Hidrográficas. Fortaleza: Edições UFC, 2011.

RODRÍGUEZ, José Manuel Mateo; SILVA, Edson Vicente da. Planejamento e gestão ambiental: subsídios da geoecologia das paisagens e da teoria geossitêmica. Fortaleza: Edições UFC, 2013.

ROSS, Jurandyr Luciano Sanches. Geomorfologia aplicada aos EIAs-RIMAs. In: GUERRA, Antônio José Teixeira; CUNHA, Sandra Baptista da.Geomorfologia e meio ambiente. 3 ed. Rio de Janeiro: Bertrand Brasil, 2000.

ROSS, Judandyr Luciano Sanches; PRETTE, Marcos Estevan, Recursos hídricos e a bacia hidrográfica: âncoras do planejamento e gestão. Revista do Departamento de Geografia, v.12, p.89-121, 1998.

ROSS, Jurandyr Luciano Sanches. Análises e sínteses na abordagem geográfica da pesquisa para o planejamento ambiental. Revista do Departamento de Geografia, v.9, p.65-75, 1997.

ROSS, Judandyr Luciano Sanches. Análise e síntese na abordagem geográfica da pesquisa para o planejamento ambiental. Revista do Departamento de Geografia, v.9, p.64-75, 1995.

ROSS, Judandyr Luciano Sanches. Análise empírica da fragilidade dos ambientes naturais e antropizados.Revista do Departamento de Geografia. V.8, 1994.

ROSS, Jurandyr Luciano Sanches. O registro cartográfico dos fatos geomorfológicos e a questão da taxonomia do relevo. Revista do Departamento de Geografia, São Paulo, v.6, p.17-29. 1992. 
ROSS, J. L. S. e MOROZ, I. C. Mapa geomorfológico do estado de São Paulo. São Paulo, DG-FFLCH-USP, IPT, FAPESP, 1997.

SABESP - Companhia de Saneamento Básico do Estado de São Paulo. Gestão Ambiental. Disponível em $:<$ http://site.sabesp.com.br/site/sociedademeioambiente>,acesso em maio de 2011.

SOARES, F. B. Planejamento e Zoneamento Ambiental da Bacia Hidrográfica do Manancial Balneário da Amizade nos municípios de Álvares Machado e Presidente Prudente - São Paulo/ Brasil. Dissertação de mestrado. FCT/UNESP, 2015.

TROMBETA, Letícia R. Planejamento Ambiental da Bacia Hidrográfica do Córrego Guaiçarinha, Município de Álvares Machado, São Paulo, Brasil. Dissertação de mestrado. FCT/UNESP, 2015. 